\title{
The Role of Smile In Social Life
}

\author{
$\mathrm{PhD}$. Trandafir Lenuța \\ "Al. I. Cuza" Police Academy, O.P.S.N.Bucharest, Romania
}

\begin{abstract}
Based on previous work showing that sex is a "diffuse status cue" the hypothesis that women smile more than men because of status differences between the sexes was evaluated Status was manipulated by assigning men and women to the roles of interviewer (high power) or applicant (low power) in simulated job interviews with either male or female partners. As predicted, overall, applicants smiled more than interviewers, demonstrating that smiling does reflect status. However, the sex composition of the pairs also influenced smiling frequency. Male interviewers smiled significantly less than their applicant partners, whereas female interviewers did not. The results suggest that, compared with females, males may more readily experience power and dominance as concomitants of high-status roles, which may then be reflected in the frequency of their smiling.
\end{abstract}

keywords:- Smile, women, men, job, social life

In the early years, Chelsea Thomas was a happy and normal child without any problem. Chelsea was born with Möbius syndrome - is missing the nerve which transmits the information from the brain to the facial muscles. Consequentlythe little girl always have a look insufferably, unhappy. She do not show no expression as she looked at her favorite show or she was meeting with her friends. In 1996, Chelsea has undergone several medical procedures, the surgeons making transplanted her muscles on both sides of the mouth, and today the little girl can finally, to do what the most people have of themselves: to smile.

Temple Grandin is a biologist whose empathic understanding of the animals in the suffering gave him the opportunity to do research and improve certain conditions for livestock in the United States. She have successful in scientific community, she is also a talented writer ... but she is suffering from a particular form of autism. T. Grandin has observed that her emotions are different from others: it may feel the pain of the animals, but she can not feel the pain of people. She do not know what signifying a romantic love; Shee was not impressed by sunrise. Being incapable to feel her emotions, she can not read the emotions of others.

The cases like these, of persons who are suffering from emotional problems and illustrates the importance of the emotions and the ability to express them.

The emotions are the heart and the soul of the human experience. If you are not nervous, you do not you'll never problems with an exam, an interview, or the first date. But ... you'll never understand the magic of music. You will never understand the pain of losing someone you love, not because you do not know what means sorrow, but do not know what means love. You do not ever laugh because you do not ever seem to you something funny.

But we are talking at the same time, and other emotions: anger, jealousy, shame, guilt, grief or unrequited love. THE PARADOX of emotions is that we can not live with them, but we can not live without them.For a very long period, the emotion was viewed as the opposite of thought. The heart (the emotion) pushes you to go in one direction, while the head (reason) shows you the opposite route. The difference between thinking and feeling has aroused many debates in the history of science. The emotions and the cognitions they are two separate processes in conflict, or they are inextricably linked? We can to control the emotions, or these control us? The thinking is always rational and the the emotion is irrational?

The psychologists made considerable efforts to try to respond to these questions. They have investigated the role of emotions in every area of social life: motivation, stress, moral development, personality traits, decision making, reasoning, mental disorders, prejudice, perception (Wade and Travis, 1998). They observed the whole experience of emotions involves three influences: physiological changes of the face and the body, cognitive processes (interpretation of the events) and the culture - the experience and expressing emotions.

The human emotions can be compared to a tree: the biological capacity are root and stem _; the thinking and the explanations create the branches, while the culture is the gardener who takes care of the tree and try to cultivate and others obtaining the seeds from the first. And yet, the smile is a universal sign of the friendship and the approving (Rathus, 1999, 419). 


\section{THE SIDE OF EMOTIONS}

The most obvious place for the expressing of emotions is the face. There are some facial characteristic facial expression accompanying the anger, the fear, erotic arousal or other passions _ _, wrote Aristotle. Later centuries, Charles Darwin, in his classic work "The Expression of the Emotions in Man and Animals" 1872 emphasize that some of the facial expression like the smile, the frown, the grimaces, harsh looking consequence represents the consequence of ontogenesis. Such expressions have evolved and because they allowed of our ancestors to distinguish betwwen a friendly stranger and hostile one. For more than 30 years, Paul Eckman and his collaborators have gathered information on the universality of seven basic facial expression of emotions: the anger, the happiness, the fear, the surprise, the disgustthe sadness and the contempt (Ekman, 1994; Ekman and Heider, 1988 by Wade and Travis, 1998, 387, Ekman et al., 1987). In all cultures which they have studied - Brazil, Chile, Estonia, Germany, Greece, Hong Kong, Italy, Japan, New Guinea, Scotland, Sumatra, Turkey and the United States - the great majority of interviewees have recognized the emotional expressions showing the others subjects from other cultures. And even members of some isolated tribes who have never seen a movie or have not read a magazine (Fore from New Guinea or Minangkabau from the west of Sumatra ) they could recognize the emotions expressed in at photos of some persons totally unknown.These conclusions do not mean that any person within of a company can recognize the same phrases in all situations. Paul Ekman (1994) formulated the neurocultural theory to emphasize two factors involved in the facial expression:

- a universal neurophysiology of facial muscles associated with certain emotions;

- the cultural particular variations in the expressing of emotions.

Thus while most individuals from most cultures can recognize the basic emotions sometimes a minority fails this working. Into a meta-analysis for the 20 studies conducted in the the western cultures, for example, 95 percent of subjects have recognized the happy faces, but only to 78 percent have recognized the expression of sadness and anger; another meta-analysis of 11 studies made in other cultures, 88 have recognized the happy faceswhile only 74 percent have recognized the sadness and only 59 percent the anger (Ekman, 1994).

Of course, not always we express our emotions or feelings. Not always we react when we are angry. We can feel anxiety or tension, but showing a smiling face. Paul Ekman and his collaborators have created a (Facial Action Coding System The - FACS) - this system allows the researchers to analyze and identify each of the nearly 80 facial muscles, as the muscle combinations that are associated emotions. When people 's trying to hide their true emotion laid, they use other muscle groups. For example, a genuine smile lasts only two seconds, a fake smile lasts at least 10 seconds (Ekman, 1994; Ekman, Friesen and O'Sullivan, 1988).

The facial expressions serve two purposes: it expresses the states inner and helps us to communicate with each other. This communication begins in early the newborn stage - the expressions of anger, happiness or disgust are visible for all parents (Izard, 1994b; Stenberg and Campos, 1990). All mothers, no matter where they are - USA, Germany, Greece, Japan - "contaminate" their babies with joy good humor by appearing with a happy expression (Keating, 1994). From the first year of life, the children begin to change their behavior by observing their parents emotions and reactions, and this capability has the adaptive worth and survival.

The facial expressions can help the people to communicate with themselves, being the able to recognize their own emotions. As outlined by William James, we are not frowning because we are angry, sometimes we feel angry because we frowning because we are angry. In the feed-back facial, facial muscles send to the brain a message about basic emotions that must expressed (Izard, 1990; Tomkius, 1981). When the individuals are asked to contract the muscles of the face in different ways, often they claim that they have changed the pattern emotions of the of facial muscles. A young man described: "The moment when the jaw was clenched and the forehead frowned, I tried to be not angry, but I failed. My emotions have begun to change in depending on how I contracted the edges "(Laird, 1974). And even of voluntary facial expression influences the nervous system. If "put" an angry face, the heartbeat will be faster compared to the situation in which "put" a happy face (Levenson, Ekman and Friesen, 1990).

When the individuals are told the _ to contracts facial muscles involved to smile (but are not trained to smile) and then are asked to look at a cartoon, they will appreciate the film as compared to the situation a lot more fun when they contract the muscles in a way incompatible with a smile (Strack, Martin and Stepper, 1988). Some researchers (Carrol and Russell, 1996) Paul Ekman contradicted the assumption that basic facial expression has universal significance: the interpretation of any expressionargue the two researchers is not automatic: it depends on the context in which it is observed the respective emotional expression.

Some research has shown that the facial expressions can or can not correspond to our inner states and that they first appear to signal our intentions towards another person (Fridlund, 1994). When we are, for example, at home, alone, we can feel very good, very happy but it is very unlikely that we will smile. The smile can happen when you meet with someone, and even if that does not make you happy, it can mean "I am delighted to see you again" or "Do not be mad at me". In a study done with 22 gold Olympic medals, notice while they were on the podium during the prestigious awards ceremony, it was shown that they have and only 
smiled when they came into contact with the authorities or the public, but not when they were alone - and yet it was assumed that they were happy and always (Fernández-Dols and Ruiz-Belda, 1995). How can we not give if you're an Olympic gold medalist? And yet ... the culture and the context play a very important role, influencing the timing and the manner in which we express our sentiments.

\section{THE ASSUMPTION OF THE FACIAL FEEDBACK}

In general, the facial expressions reflect the emotional states. In fact, many emotions give rise to certain patterns of electrical activity in certain facial muscles and the brain (Cacioppo et al., 1988).

The assumption of the facial feedback advances the idea that the causal relationship between emotions and the facial expressions can work in the opposite direction:

The free expresion of outward signs of an emotion leads to an intensification of it. Of the other part, strongest possible the repression of all outward signs can decrease the intensity of emotions (Darwin, 1872 after Rathus 22, 1999, 420).

And therefore a natural question arises: A smile can cause a good mood?

The psychological research came to several interesting conclusions about the assumption of the facial feedback (Eckman, 1993). A topic provoked him to smile, for example, leading them to a better mood (Basic Behavioral Science Task, 1996c) and thus a cartoon reviewed more favorably. When the subjects have been frowned they evaluated aggressively the cartoons (Strack, Martin and Stepper, 1988).

What is the connection between emotion and facial feedback? A possible connection is the excitation (arousal). An intense contraction of the facial muscles similar to that existing in an emotional state characterized by excitation emphasizes fear, which in fact strengthens the emotional response. P. Eckman (1993) demonstrated that the so-called Duchenne the smile can cause pleasant feelings.

The emotional expressions have many functions, but only a part of them are part of the emotional picture. And even Paul Ekman stressed that "There is clearly without express facial emotions and the facial expressions without any emotion be based."

The smile is usually associated with the positive emotions like the happiness, the joy and the pleasure. More than that, the intercultural studies made by P. Ekman and Friesen W. (1971) as well as those made by C. Izard (1971) showed that adults from a variety of cultures put the smile to link up with the positive emotions . Although these studies have been criticized later, however, it demonstrated that the smile is associated with the positive emotions rather than negative ones.

Nevertheless, there are many information that the communicate not and does not always express the positive emotions (Caplowitz-Barrett, 1999). The researches have proved that:

1. There are different types of smile,_ each suite being a certain significance;

2. the negative emotions may be accompanied by the smile;

3. the smile is strongly influenced by social, communication with social functions (thus having more to do with the type of social communication and less with emotions).

4. While there are gender differences in terms of the smile.

Most of them individuals assume that the smile is associated primarily with a positive emotion, and in a wide variety of crops, with his help, notice is also a positive emotion. The smile is displayed in all cultures studied, and all this information, taken together, indicate that the joy and the happiness represents the consequence of the universal emotions.

The smile has firstly the communication function (Fridlund, 1994) - Duchenne the smile inform about the availability of of playing and affiliationwhile non-Duchenne the smile inform that the person is ready to reassure.

Even if the smile represents the consequence of an expression of the positive emotions, the sociality can have a great influence on the probability of occurrence thereof. Barrett K. and J. Campos (1987) pointed out that the social communication is one of three fundamental functions of the smile; Thus, the social communication and the social context must be taken into consideration when we consider an emotional response. A. Fridlund (1994) demonstrated that perceived the sociality of the situation (the other should not necessarily be present) affect the probability of the smile. For example, using an apparatus for detecting the smallest movements zygomatic muscle (at the smile), A. Fridlund (1991) that teenagers smile the least they are alone and more when a friend:

- it is in another room, being busy with another load;

- it is in another room busy with the same load (looking at a videotape);

- just been in another room and had the same load as the subject.

Other studies have shown that the interactions causes polite the smile. J.M. Fernandez-Dols and RuizBelda MA (1995) observed that Olympic gold medalists smile not than when interacting with others.

More than that, these effects are not well socialized of adults own. In a study by K. Schneider and Joseph I. (1991), the preschool subjects placed in learning situations, they smiled more when they were in front 
of the experimenter, even though they have failed to make the load. Scanlon S. Jones and others $(1991,1990)$ demonstrated little ones (10 months, 17 months) smiling more, playing with toys when their mother is careful to her compared to the situation where the mother ignores them and read a magazine (even if the little ones are not bothered by the lack of attention). Hains S. and D. Muir (1996) founded that those aged 3 and 6 months smiled more when interacting with adults and have visual contact with them compared with the situation when have not visual contact.

\section{THE GENDER DIFFERENCES}

There is, in the society, expectations that the women to smile more than men, and research has confirmed that these expectations are well grounded - the women and the children smile more than men. H. Reis et al. (1990) observed that the smiling people are perceived to be more sociable, but less independent and masculine. The woman less than masculine smile more when they meet men and when with friends (Cashdan, 1998).

A lot of studies have explained the gender differences in terms of the smile by differences in the power / the status between women and men. These interpretations were confirmed by research conducted by F. Deutsch (1990) in which both women and men who they had accomplished their loads confers more powers on (intervieviator) they smiled less than those that were invested with loads gives them less power. The men who have higher testosterone levels are smiling less and are perceived as being more potent compared with those who had lower testosterone levels. at the same time, the women who smile more they have a higher sociometric status (they are perceived by the group as being more popular), and the men and the women perceived to be popular have been described as being better leaders.

In several studies, the women smiled more when they were with other women, compared with the situation when they were with men. These results lead to refute the assumption that differences in the power is the main reason that the women smile more than men. It was also demonstrated that a woman who smiles not necessarily mean that it is more submissive. The gender differences come rather from that the smile makes you more attractive, more friendly and more concerned about others (traits that women are socialized), but also when we speak of that prophecy self accomplished ${ }^{l}$ - the society expects the women to smile more.

\section{THE ATTRACTION FOR DIFFERENT TYPES LAUGHING}

The laughter is like a fingerprint, unique and personal each one of us. But have you noticed the effects that the laughter can have on others us: the one is communicative and gives us good disposition the other annoys us terribly (Ciccotti, 2007, 109).

Free yourself deductions and open laugh. Despite what you might think, this behavior would rattle your entourage certainly less than if giggle to himself (Ciccotti, 2007, 111).

\section{THE SMILE - lie detector}

You smile when you really want to smile.

The lips, like the eyes, are capable of reflecting the finest soul experiences. This is why the famous smile of Mona Lisa attracts by hundreds of years by its mystery, millions of eyes. But most usual and modest smile that appears on his face for a second also is occasionally able to tell us a lot about a man.

The smile usually expresses friendship, the need for approval, openness in communication. But whereas the smile can reflect many different reasons, we must pay attention to the interpretation.

"Just look, are not at all dangerous and I'm not preparing to bite!" approximately such a message, according to the scientists transmitter the most ancient human smiles. They were a peaceful gesture, only by lips the smile reveals teeth loosen and united in a non-threatening position.

If the significance of the smile now would be the same!.. But the smile is no longer the same, it was complicated to infinity, can be cunning, fawning, regardless, forgery, victorious ... He is only slightly lower than the look, through the variety and his expressiveness.

Thus the exaggerated smiling can be a manifestation of a diseased needs approval or of humility to the chiefs, and may not necessarily mean anything, be a polite original company, a mask.

There is a direct connection between the mood, physical and smile. If in soul is sadness, the smile will be full of suffering. If you are well, it is happy the smile. The peace of mind is reflected in the smile always. The people receives the smiles gratefully expressing goodwill or friendship. A smiley face more often causes goodwill. In life there are always more problems; the people who know how to smile defeat them with spiritual and physical fewer losses.

\footnotetext{
1 "The incorrect definition of the situation, which becomes true because the people accept this incorrect situation and acts which favor its transformation into reality of people's the trend of people to respond and to act on the stereotypes, predisposition that can lead to validation of false definitions" (cited Radu-Geng, 2003, 267). 
Since we can not to describe all the human lip movements, to refer just to the basics of "smilelogy".

The social smile. The humor and the jokes have nothing to do with him. This smile appears when the people greet or communicate with each other. He can appear unintentionally when your eyes of meet the the eyes of the interlocutor. Create a mood friendly, peaceful, contributes to acommunication enjoyable, warm. top teeth.

The distinguishing feature: the lips, at the social smile, or higher, are disposed so that only reveals the

Sometimes it is a requirement of the workplacefor example the flight attendants (Hochschild, 1983). This kind of _ is found in women compared to men because they are educated in this regard, to the detriment of concern for the feelings of others their own feelings (Fischer, 1993; Grossman and Wood, 1993). They do not smile more because they feel happiest, but to reassure and to avoid the differences (Henley, 1995 by Wade and Tavris 1998, 410). If the women do not smile as much as the others expect, they are not enjoyable, even smiling, in fact smiling as much as the men.

The children learn this working very early. The research has shown thatsince the two months of age, the babies display this type of smile, "_ the social smile" as a response to human faces, and from three or four months they start to laugh (Sroufe and Waters 1976 after Baron, 1989 , 310). From the 6 years of age is observed that they begin to know where and when to mask their feelings and to show a "polite smile" - for example, when receiving a gift who they do not like. From this age is observed the gender differences: girls better than boys masking the negative sentiments. As adultsthe women show anger, but with a smile, a mixed message that may be misinterpreted by friends, husband or children (Deutsch, LeBaron and Fryer, 1987).

In social life, the smile has a very important role. When we want to establish a closer relationship with someone, closer to the other person that we tend to show that we are interested in and honestly smiled, revealing teeth and wrinkling us corners of the eyes. To be a good listener, the message that we conveyed feelings can be increased by surprise of the speaker will reflect on the listener book as the "mirror". This does not mean to laugh out loud when the speaker smile, but a smile when he laughs (Quill, 2001).

Big smile. In such a smile, on the contrary, sometimes seen all 32 teeth, and near the mouth and nose are formed deep creases. It's probably the most honest and natural smile that arises spontaneously when the man is amused by the something or enjoys. It is true he has an aggressive shade (it is the result of someone's clumsy actions). Some consider the big smile a sign of poor growth and strive to "re-educate" in social smile.

Simple smile. More often than it occurs when a person smiles _ himself, his thoughts and fantasies. The lips are stretched, but without straining, teeth not seen. The head can be easily bent, dropped or tilted to one side. Near the nose and mouth puckering light are emerging

Joking smile. It is a waiting smile that precedes a big smile, really. So the speaker smiles when you expect from your next portion of funny stories, or the spectator when evolve a known comedian. The lips are widely distant the corners of the mouth are slightly raised, but the teeth is not yet visible .

Wry smile. Looks like simple smile, but the corners of the mouth are left crooked down with a nasty shade, threatening. Such a smile appears if your interlocutor is in trouble or does not approve your words. Express soon presumption or contempt than an open aggression.

Struggled smile. Not such a The lips are slightly tight, stretched and slightly raised the corners of the mouth. One also smile show artificially and tensed _, looks a lot like forced smile. It is true, the latter can show clenched teeth.

Fake smile. It is noted by failing to forms the wrinkles at the corners of their eyes honest smile , naturally. For that, a honest smile, the eyes are also involved, especially in the "crow's-feet" (Lelord and André 2001, 95). The eyes remain serious. So smile the people at the photographer when they die of boredom or visit. This type of smile goes easily into a sneer (fig. G).

Does we can always to discern after the facial expression, the true feelings of the simulated? The answer comes by itself: not even close. But there are checking your conclusions and intonation, the words, the gestures, in a word, all the arsenal that a man is using in communication. to cheat a triple defense is more complicated. But even after the lips can only draw conclusions quite accurate about the true intentions of your interlocutor. You only have to know to notice the secret signs that you suggest.

The anthropologist Karsten Nimitz German studying video tape recorder with the help of his dynamic smile, he determined that the impression of sincerity or hypocrisy smile appears according to speed with which enlargement raises by the corners of the mouth and the eyes, with short further movement of the eyelids. The researcher points out that a widening of the eyes too long without closing briefly in combination with the smile be construed as a threat. On the contrary, the closing for a short time of the eyes is a peaceful element of the mimic. He who would give like smiles understandable: "I do not expect anything bad from you, you see, even I close my eyes." 


\section{THE FEATURES OF NATURAL AND THE UNNATURAL SMILE}

You know you to distinguish a honest smile by a fake one? This useful skills lets you know if someone really enjoys that meet you.The first who notice this difference between the two types of smile is a French physician in the nineteenth century, Duchenne de Boulogne (1806 -1875). Being not only a good diagnostician, Duchenne also used two of his century inventions, thw photography and the electricity: Walking two electrodes on a subject's face (who accepted the experience), he achieved a real _ map of different human expressions, depending on the muscles involved. Darwin published his photos and quoted often in his work on the emotions. As homage to Duchenne, Paul Ekman has proposed to name the true smile of jthe oy "Duchenne smile".

The orbicularis muscle is not fully contracted to an honest smile, but only to the external, coming down while the eyebrows. simple "narrowing" of the eyes the smiling _ is not enough to obtain a honest smile. We can thus distinguish three types of actors or politicians, depending on the quality of their smile.

These are subtle differences between the three types of the smile can be seen in children: her smile "a la Duchenne" when they see their parents, but addressed smiles "empty" or "false" to a stranger. Similarly, the way haow spoeses they smile when they meet, sincere or fake, is a great indicator of the general state of their marriage. But it may be a warning signal for a careful husband.

For the correct understanding of the smile, the features must known naturally and unnatural smile. When it is naturally, shortens the bottom of the circular muscle of the eye. In this situation raises the lower eyelid. But when the smile is false, smileling only the lips.

The mimic of the mouth is much easier to control than the forehead and the eyes movements, so just in the upper face must look the features showing the insincerity. A man with a fake smile can not replicate the creases specific of the real smile under the lower eyelids and from the corners of his eyes. His eyes do not laugh.

- fake smile can appear slightly earlier or later than it should be after the discussion purposes. It may occur suddenly and absolutely inappropriate.

- You should be careful if the smile remain on the face too long, because the natural life of a the smile is an average of four seconds (if, of course, is not accompanied by long Homeric laughter).

- Remember that in many countries to smile to a stranger is a common obligation and not an excuse to get acquainted, in terms of the women, they are smiling more often and with more pleasure than men, so their feminine nature is called to give joy to those around.

\section{AKNOWLEDGEMENT}

This work was possible with the financial support of the Sectoral Operational Programme for Human Resources Development 2007-2013, co-financed by the European Social Fund, under the project number POSDRU/159/1.5/S/138822 with the title "Transnational network of integrated management of intelligent doctoral and postdoctoral research in the fields of Military Science, Security and Intelligence, Public order and National Security - Continuous formation programme for elite researchers «SmartSPODAS»".

\section{BIBLIOGRAFIE}

[1] Bachorowski, J. A. şi Owren, M. J. (2001). Not all laughs are alike: Voiced but not unvoiced laughter readily elicits positive affect. Psychological Science, 12, 252-257.

[2] Baron, R. A. (1989). Psychology. Allyn and Bacon: Boston.

[3] Ciccotti, S. (2007). 150 de experimente în psihologie pentru cunoaşterea celuilalt. Mecanismele comportamentelor cotidiene. Iaşi: Editura Polirom.

[4] Chelcea, S. (coord.). (2004). Comunicarea nonverbală în spațiul public. Bucureşti: Editura Tritonic.

[5] Collett, P. (2003/2005). Cartea gesturilor. Cum putem citi gândurile oamenilor din acţiunile lor. Bucureşti: Editura Trei.

[6] Crăciun, A. (2000). Valenţele diagnostice-terapeutice ale râsului. Psihologia. Societatea Ştiinţă şi Tehnică S.A., 4, 5-8.

[7] Fernandez-Dols, J. M. şi Ruiz-Belda, M. A. (1995). Are smiles a sign of happiness? Gold medal winners at the Olympic games. Journal of Personality and Social Psychology, 69, 1113-1119.

[8] Hall, J. A., Carter, J. D., Jimenez, M. C., Frost, N. A. şi Smith LeBeau, L. (2002). Smiling and relative status in news photographs. Journal of Social Psychology, 142, 500-510.

[9] Lăţea, P. (1994). Funcţiile psihosociale ale râsului. Psihologia. Societatea Ştiinţă şi Tehnică S.A., 4.

[10] Lelord, F. şi André, C. (2003). Cum să ne exprimăm emoţiile şi sentimentele. Bucureşti: Editura Trei.

[11] Ognev, I. şi Russev, V. (2005). Securitatea psihologică. Bucureşti: Editura Fundaţiei Culturale Ideea Europeană.

[12] Pease, A. şi Pease, B. [2002] (2003). El e cu minciuna, ea vorbeşte într-una. Bucureşti: Editura Curtea Veche. 
[13] Provine, R. R. (1992). Contagious laughter: Laughter is a sufficient stimulus for laughs

[14] Quilliam, S. (2001). Tainele limbajului trupului. Bucureşti: Editura Polimark.

[15] Rathus, S. A. (1999). Psychology in the new millenium. Harcourt Brace College Publishers: Fort Worth.

[16] Wade, C. şi Tavris, C. (1998). Psychology. Addison Wesley Longman, Inc.: New York.

[17] http://www.psy.miami.edu/faculty/dmessinger/c_c/rsrcs/rdgs/emot/Afterword_to_All_smiles_are_positiv e.pdf 